
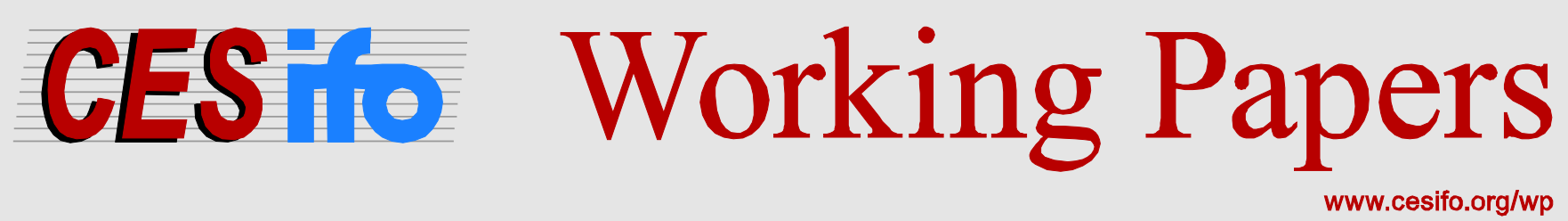

\title{
Renewed Momentum in the German Housing Market: Boom or Bubble?
}

\author{
Xi Chen \\ Michael Funke
}

\author{
CESIFO WORKING PAPER NO. 4287 \\ CATEgORY 6: FiscAl POLICY, MACROECONOMICS AND GROWTH \\ JUNE 2013
}

An electronic version of the paper may be downloaded

- from the SSRN website:

- from the RePEc website:

- from the CESifo website:

WWW.SSRN.com

Www.RePEc.org

www.CESifo-group.org/wp

\section{CESifo}




\title{
Renewed Momentum in the German Housing Market: Boom or Bubble?
}

\begin{abstract}
The renewed momentum in the German housing market has led to concerns that Germany is vulnerable to asset price shocks. In this paper, we apply recently developed recursive unit root tests to detect the beginning and the end of potential speculative bubbles in Germany over the sample period 1987Q3 - 2012Q4. Overall, we find that actual house prices are not significantly disconnected from underlying economic fundamentals. Thus, there is no evidence of speculative house price bubbles in Germany.
\end{abstract}

JEL-Code: C220, C530, E520, R310.

Keywords: Germany, house price bubbles, right-tailed unit root tests.

\author{
Xi Chen \\ Hamburg University \\ Department of Economics \\ Hamburg / Germany \\ xi.chen@wiso.uni-hamburg.de
}

\author{
Michael Funke \\ Hamburg University \\ Department of Economics \\ Hamburg / Germany \\ michael.funke@uni-hamburg.de
}

Hamburg, June 2013

We are grateful to Konstantin Kholodilin (DIW Berlin) for making available the OECD house price database which we have used in the empirical applications. The usual disclaimer applies. 


\section{Introduction}

After more than a decade of stagnating or even falling house prices, the German real-estate market began to surge in 2010 and house prices in larger cities have experienced large mark-ups. On the one hand, the prevailing low interest rate environment and expectations that central banks in advanced economies will not tighten monetary policy in the near future play a role in this development, as. low interest rates can fuel excess borrowing and push asset prices ever higher. On the other hand, the euro crisis matters. Not only are German households acquiring more real estate, but foreigners see Germany as a safe haven. In light of increasing house prices and the previous experience of how the bursting of real-estate bubbles triggered 2008-2009 recessions in several countries, there are increasing concerns that Germany might be destined for a similar fate. Unbounded enthusiasm could be a real danger in this context. History is replete with examples of plenty of prolonged periods of low interest rates that encouraged speculative housing bubbles. ${ }^{1}$

Prior to the global recession of 2008-2009 and the associated disruptions in financial markets, asset price bubbles were often considered as a sideshow to macroeconomic fluctuations. The global recession demonstrated painfully that this dominant pre-crisis presumption was dangerously wrong. A rapidly growing literature is now seeking to remedy this shortcoming and has begun to address this knowledge gaphead-on. In particular, Agnello and Schuknecht (2011), Claessens et al. (2009), Hirata et al. (2013) and Igan and Loungani (2012) have taken a global perspective and have provided an assessment of the linkages between house prices and real economic activity. There are three reasons why a house-price bubble might cause more harm on bursting than a stock price bubble. First, house prices have a bigger wealth effect on consumer spending largely because more people own property than own shares. Second, people are much more likely to borrow to buy property than to buy shares. Third, a large decline in property prices leaves some households with negative equity. Consequently, housing busts have a greater effect on banks, which are typically heavily exposed to real estate. Falling house prices lead to an increase in banks' non-performing loans, and as their collateral shrinks, so does their capacity to lend. These studies also discuss the surprisingly high synchronisation of house price downturns as observed during the global financial crisis, which is likely to have exacerbated the deep recession. ${ }^{2}$

At the same time, a new empirical literature on early warning indicators has emerged. ${ }^{3}$ This literature reflects a desire to better identify speculative bubbles in real time. Since boom-and-bust cycles possibly lead to serious serious financial and macroeconomic strains, central banks have reconsidered their monetary policy strategies with regard to asset bubbles. Prior to the global recession 2008-2009, the

\footnotetext{
${ }^{1}$ For example, in Ireland and Spain cheap euro-denominated loans led housing to appear inexpensive and resulted in housing bubbles in the early 2000s.

${ }^{2}$ Another relevant strand of literature concerns the role of housing within dynamic stochastic general equilibrium (DSGE) models. See, for example, Funke and Paetz (2013), Iacoviello and Minetti (2008), Iacoviello and Neri (2010). This literature is beyond the scope of the brief review presented in this section.

${ }^{3}$ See, for example, Alessi and Detken (2011), Crespo Cuaresma (2010), Gerdesmeier et al. (2012) and the literature cited therein.
} 
European Central Bank (2002) had expressed doubts about the ability to detect bubbles with a sufficient degree of certainty. A first change of course occurred in 2005, when the European Central Bank (2005) argued that, firstly, there are a number of tools to detect asset bubbles and, secondly, emerging asset bubbles should be taken into consideration when making interest rate decisions. In the light of the global recession the European Central Bank (2010) has finally acknowledged that the case for preemptive monetary policy responses to emerging asset bubbles has been strengthened. In light of the recent momentum in German house prices, the question of house price bubbles is also a matter of concern for the Deutsche Bundesbank. In the same spirit as the European Central Bank, the Deutsche Bundesbank (2012) has emphasized that a combination of low interest rates and high liquidity may pose a considerable danger to financial stability. Furthermore, easy monetary policy and especially unconventional monetary policy that lowers interest rates all along the yield curve facilitate unnatually low risk premia. Therefore, monetary policymakers should deploy micro- and macro-prudential policy tools to cool down housing markets in case of emerging price escalations. In other words, a gradual policy change from a "benign neglect" towards a "leaning against the wind" strategy has occurred. This shift of policy implies that now, more than ever, monetary policymakers are willing to dampen asset bubbles at the early stage of their formation. ${ }^{4}$

Against this backdrop, our study complements and extends the existing literature in several ways. In particular, we employ a new statistical test pioneered by Phillips and Yu (2011) and Phillips et al. (2012) and up-to-date house prices data to assess the renewed momentum in the German housing market. We find no evidence of an emerging speculative housing bubble in Germany at the present moment. It goes without saying that this is just a snapshot of the current situation and no clean bill of health can be given for the future.

The structure of this paper is as follows: section 2 reviews some theoretical and econometric issues related to housing valuation and bubble identification. In section 3, we introduce the house price database. In section 4, we proceed by discussing the results of the econometric diagnostics. The final section concludes with a summary and suggestions for further research.

\section{Modelling and testing strategy}

In the first stage, we need to define bubble periods. Based on this, we can then identify inflated house prices and bubble periods. The classical literature on rational bubbles derives conditions under which bubbles can occur when all agents are perfectly rational. Classical rational house price bubbles can arise because of the indeterminate aspect of solutions to rational expectations models. The house price that

\footnotetext{
${ }^{4}$ Given the difficulties of detecting emerging housing bubbles in real time, the situation policymakers are facing is one of Knightian uncertainty. The associated question on the optimal dynamic path of monetary policy is of great interest, but lies beyond the scope of this paper. Agur and Demertzis (2013) have recently shown that financial stability objectives make optimal monetary policy more aggressive, i.e. monetary policy tightens as soon as bank risk profiles increase. In other words, the optimal approach to dealing with unknown unknowns is to move away from the danger zone. For an axiomatic foundation of Knightian uncertainty, see Gilboa and Schmeidler (1989).
} 
agents are prepared to pay today depends on the expected house price at some point in the future. But the latter depends on the expected house price even further in the future. The resulting process governing house prices does not pin down a unique house price level unless, somewhat arbitrarily, a transversality condition has to be imposed to obtain a unique solution. However, in general, the possibility that house prices may systematically deviate from their fundamental value cannot be ruled out. Even if risk-neutral agents are perfectly rational, the actual house price may contain a bubble element, and thus there can be a divergence between the house price and its fundamental value. The resulting real estate bubble is an upward house price movement over an extended range that then suddenly collapses.

Our goal is to ascertain how house prices evolve over time, given the behaviour of fundamentals. Time is discrete. In the modelling framework, fundamental house prices $H_{t}$ can be represented as follows:

$$
H_{t}=\left(\frac{1}{1+r}\right) E_{t}\left(R_{t}+H_{t+1}\right)
$$

where $E_{t}$ is the expectations operator, $R_{t}$ is the rental value at time $t$, and $r$ is the discount rate. To solve the model, we need to eliminate the term involving the expectation of the future value of the endogenous variable. It is straightforward to show that the fundamental house price $H_{t}^{F}$ can be solved under rational expectations by repeated forward substitution. This implies

$$
H_{t}^{F}=\sum_{j=1}^{\infty}\left(\frac{1}{1+r}\right)^{j} E_{t}\left(R_{t+j}\right)
$$

The logic of equation (2) is that house market prices contain expectations of future rents. No specific assumptions are made about the process followed by $R_{t}$. The rational bubble components $B_{t}$ follow

$$
B_{t}=\left(\frac{1}{1+r}\right) E_{t}\left(B_{t+1}\right)
$$

Solving for $H_{t}$ finally yields

$$
H_{t}=H_{t}^{F}+B_{t}
$$

Equation (4) breaks up house prices into a 'fundamental' and a 'bubble' component. Without a bubble, house prices equal the fundamental value $H_{t}^{F}$. Under bubble conditions house prices may show an explosive behaviour inherent in $B_{t}$. If $B_{t}$ is strictly positive, this builds the stage for speculative investor behaviour: a rational investor is willing to buy an 'overpriced' house, since he/she believes that future price increases will sufficiently compensate him/her for both the extra payment he/she has to make and 
the risk of the bubble bursting. In that sense, the house price bubble is a self-fulfilling prophesy. Eventually the bubble implodes, house prices fall with a sharp correction, and deleveraging occurs. In recent years, a new generation of behavioural models capable of generating bubbles has emerged. This literature is quite broad, so we will touch on only a few important papers here. The unifying feature behind this class of model is bounded rationality for at least one group of agents. In the behavioural models, a bubble may arise when asset prices overreact to a potentially informative signal about fundamentals. Behavioural models can be classified into three categories. Firstly, differences of opinion and short sale constraints may generate asset bubbles. Scheinkman and Xiong (2003) provide a dynamic model, in which optimistic investors exhibit bounded rationality and fail to take into account that other agents in the economy may have more pessimistic views about an asset but cannot sell that asset due to short sale constraints. Secondly, feedback trading mechanisms may allow bubbles to grow for a period of time before they eventually collapse. An example of a model that contains feedback traders is Hong and Stein (1999). The model includes two groups of traders - news watchers and feedback traders. Neither group is completely rational. News watchers do not condition on past prices. On the other hand, feedback traders do not observe the signals about the fundamentals and condition their trading decisions entirely on past asset price changes. Furthermore, new information diffuses slowly across the population of news watchers, and, therefore, asset prices react gradually to new information. Since prices initially under-react to news, the feedback strategy could be profitable and prices end up overshooting fundamentals. The reason for this is that news watchers don't know whether they are trading early or late in the news cycle. Shiller (2002) has argued that news media attention amplifies such feedback-trading tendencies in the market. Optimistic media reports may help create bubbles not because agents believe these views but because the optimistic stories may indicate the existence of other investors who do, destroying the common knowledge of rationality. Thirdly, biased self-attribution may lead to asset price bubbles. The term self-attribution was coined by research emanating from the field of psychology. Biased self-attribution leads agents to take into account signals that confirm their beliefs and dismiss as noise signals that contradict their beliefs. Daniel et al. (1998) have formulated a comprehensive model with noisy signals and agents suffering from biased selfattribution. As a result they grow overconfident, which leads to the formation of a bubble. ${ }^{5}$

Next we discuss how the theoretical frameworks can be linked to an econometric testing strategy. In the econometric literature, identifying a bubble in real time has proved challenging and remains an elusive task. In addition, subtle econometric problems result from finite samples. Standard unit root and cointegration tests may be able to detect one-off exploding speculative bubbles, but are unlikely to detect periodically collapsing bubbles. ${ }^{6}$ The reason is that traditional unit root tests are not well

\footnotetext{
${ }^{5} \mathrm{~A}$ frequent argument against behavioural models is that the presence of rational investors in the market should stabilise prices. Remarkably, the models of DeLong et al. (1990) and Abreu and Brunnermeier (2003) show that under certain conditions rational arbitrageurs may even amplify rather than eliminate the asset mispricing.

${ }^{6}$ Figure 1 in Chen and Funke (2013, p. R41) illustrates, at the risk of oversimplification, the taxonomy and conceptual differences between a one-off bubble versus periodically collapsing bubbles.
} 
equipped to handle changes from $\mathrm{I}(0)$ to $\mathrm{I}(1)$ and back to $\mathrm{I}(0)$. This makes detection by cointegration techniques all the more difficult, due to bias and kurtosis [Evans (1991)]. ${ }^{7}$

A nuanced and persuasive approach to identification and dating multiple bubbles in real time has recently been pioneered by Phillips and Yu (2011) and Phillips et al. (2012). ${ }^{8}$ The idea is to spot speculative bubbles as they emerge, not just after they have collapsed. Their point of departure is the observation that the explosive property of bubbles is very different from random walk behaviour. Correspondingly, they have developed a new recursive econometric methodology interpreting mildly explosive unit roots as a hint for bubbles. If we consider the typical difference of stationary vs trend stationary testing procedures for a unit root, we usually restrict our attention to regions of 'no more than' a unit root process, i.e. an autoregressive process where $\rho \leq 1$. In contrast, Phillips and Yu (2011) model mildly explosive behaviour by an autoregressive process with a root $\rho$ that exceeds unity but is still in the neighbourhood of unity. The basic idea of their approach is to recursively calculate rightsided unit root tests to assess evidence for mildly explosive behaviour in the data. The test is a rightsided test and therefore differs from the usual left-sided tests for stationarity. More specifically, consider the following autoregressive specification estimated by recursive least squares:

$$
x_{t}=\mu+\rho x_{t-1}+\varepsilon_{t} \quad \quad \varepsilon_{t} \sim \operatorname{iid}\left(0, \sigma^{2}\right) \quad .
$$

The usual $\mathrm{H}_{0}: \rho=1$ applies, but unlike the left-sided tests which have relevance for a stationary alternative, Phillips and Yu (2011) have $\mathrm{H}_{1}: \rho>1$, which, with $\rho=1+c / k_{n}$, where $c>0, k_{n} \rightarrow \infty$ and $k_{n} / n$ $\rightarrow 0$, allows for their mildly explosive cases. ${ }^{9}$ Phillips and Yu (2011) argue that their tests have discriminatory power, because they are sensitive to the changes that occur when a process undergoes a change from a unit root to a mildly explosive root or vice versa. This sensitivity is much greater than in left-sided unit root tests against stationary alternatives. But this is not all. It should be added that bubbles usually collapse periodically. Therefore, standard unit root tests have limited power in detecting periodically collapsing bubbles. ${ }^{10}$ To overcome this drawback, Phillips and Yu (2011) have suggested using the supremum of recursively determined Dickey-Fuller $(D F) t$-statistics. The estimation is intended to identify the time period where the explosive property of the bubble component becomes dominant in the price process. The test is applied sequentially on different subsamples. The first subsample contains observations from the initial sample and is then extended forward until all observations of the complete sample are included. The beginning of the bubble is estimated as the first

\footnotetext{
${ }^{7}$ For a survey of traditional econometric bubble tests, see Gürkaynak (2008).

${ }^{8}$ The diagnostic for multiple speculative bubbles modifies a previous method for identifying one-off bubbles suggested in Phillips et al. (2011). A different class of tests for identifying periodically collapsing bubbles based on Markov-switching models has been explored in Funke et al. (2004) and Schaller and van Norden (2002), among others.

${ }^{9}$ The $\mathrm{H}_{1}$ hypothesis is motivated by the theory of rational asset bubbles, which claims that asset prices should be explosive in the presence of an asset bubble. See Diba and Grossman $(1987,1988)$.

${ }^{10}$ Busetti and Taylor (2004), Kim et al. (2002) and Leybourne et al. (2006) have shown that traditional unit root tests have low power in the case of gradually changing persistence and/or the existence of persistence breaks.
} 
date when the $D F t$-statistic is greater than the corresponding critical value of the right-sided unit root test. The end of the speculative bubble will be determined as the first period when the $D F$ t-statistic is below the aforementioned critical value. In other words, as long as the statistic has crossed the critical values, a bubble is deemed to be imminent.

Formally, Phillips et al. $(2011,2012)$ suggest calculating a sequence of $D F$ tests. Let $\hat{\rho}_{\tau}$ denote the OLS estimator of $\rho$ and $\hat{\sigma}_{\rho, \tau}$ the usual estimator for the standard deviation of $\hat{\rho}_{\tau}$ using the subsample $\left\{y_{1}, \cdots, y_{[\tau T]}\right\}$. The forward recursive $D F$ test of $H_{0}$ against $H_{1}$ is given by

$$
\operatorname{supDF}\left(r_{0}\right)=\underbrace{\sup }_{r_{0} \leq \tau \leq 1} D F_{\tau}, \quad,
$$

where $D F_{\tau}=\frac{\hat{\rho}_{\tau-1}}{\widehat{\sigma} \rho_{\tau}}$. Note that the DF statistic is computed for the asymmetric interval $\left[r_{0}, 1\right]$. In applications, $r_{0}$ will be set to start with a sample fraction of reasonable size. The limiting distribution is

$$
\underbrace{\sup }_{r_{0} \leq \tau \leq 1} D F_{\tau} \stackrel{D}{\rightarrow} \underbrace{\sup }_{r_{0} \leq \tau \leq 1} \frac{\int_{0}^{\tau} W d W}{\int_{0}^{\tau} W^{2}},
$$

where ' $\stackrel{D}{\rightarrow}$ 'denotes convergence in distribution and $W$ is a standard Wiener process. Analogously, the augmented supADF (SADF) test can be derived. Thereby, the optimal lag length of the AR(k)-process is chosen using the Akaike information criterion.

In addition, Phillips et al. (2012) have suggested employing the 'generalized' supADF (GSADF) test as a dating mechanism. The GSADF diagnostic is also based on the idea of sequential right-tailed $A D F$ tests, but the diagnostic extends the sample sequence to a more flexible range. Instead of fixing the starting point of the sample, the GSADF test changes the starting point and ending point of the sample over a feasible range of windows. In other words, it calculates the right-tailed DF statistic in a more flexible recursive manner. In particular, it varies not only the number of observations but also varies the initial observation of each regression. The supsup $D F$ statistic is then used to pin-point the presence of periodic bubbles. The supsup $D F$ statistic is obtained by taking the supremum twice with respect to the fractional window size of the regression and the ending fraction of the sample. In order to identify the beginning and end dates of a housing bubble, the supsup $D F$ statistic can then be compared with the corresponding critical value. Phillips et al. (2012) demonstrate that the moving sample GSADF diagnostic outperforms the $S A D F$ test based on an expanding sample size in detecting explosive behaviour in multiple bubble episodes and seldom gives false alarms, even in relatively modest sample sizes. The reason for this is that the GSADF test covers more subsamples of the data. ${ }^{11}$ For these

\footnotetext{
${ }^{11}$ In the interests of brevity, further technical details are not presented here. , The interested reader is referred to the above-mentioned papers introducing the right-tailed unit root testing strategy. A technical supplement
} 
reasons the continuous scale GSADF test becomes the method of choice in our application and we shall apply the GSADF test to locate periodic explosive sub-periods under real-time conditions, as shown below.

\section{The dynamics of German house prices vis-à-vis other countries}

The section begins by presenting the most recent house price surge in Germany in the context of the experiences of other OECD countries. ${ }^{12}$ A graphical tool that is very helpful in highlighting recent house price developments is a 3-dimensional scatter plot of house price developments across OECD countries for 2010, 2011 and 2012. Figure 1 contrasts the experiences of various economies in these years. The following stylised facts are noteworthy. First, within the OECD countries there are large divergences. Cases of rapidly rising house prices co-exist along with cases of constant or even falling house prices. Housing markets are depressed in southern Euroland, notably in Greece and Spain. House prices are also falling fast in Ireland and the Netherlands. This contrasting performance of housing markets reflects the broader trend towards a two-speed Euro area. Second, in several countries including Germany a strong positive house price dynamic has prevailed over the period 2010 - 2012 . Several mechanisms are at work. First, the renewed momentum in the German housing market was triggered by positive prospects for German GDP growth and employment as well as historically low mortgage financing rates. Second, the Euro crisis triggered a flight out of financial assets into real assets. Finally, the Euro crisis has also triggered an international flight to attractive safe assets. It is for these reasons that lingering worries about a German house price bubble have emerged. ${ }^{13}$ Third, as in Germany house prices have climbed towards new heights in Austria and Switzerland. ${ }^{14}$ Fourth, housing markets in several other OECD countries have experienced substantial corrections. In particular, Ireland, Spain, Greece, Portugal, the Netherlands and the U.S. experienced downward pressure on house prices and underwent severe deleveraging.

providing a complete set of mathematical derivations of the limit theory underlying the unit root tests is available at http://sites.google.com/site/shupingshi/TN_GSADFtest.pdf?attredirects=0\&d=1.

12 The seasonally-adjusted quarterly house price dataset employed in this paper stems from the Organization for Economic Cooperation and Development (OECD) which is a widely watched multi-country house price database.

${ }^{13}$ Recently the IMF has warned that "loose liquidity conditions in the banking sector may lead to excessive asset price increases” in Germany [IMF (2012), p. 39]. The recent German "growth miracle” may also have fuelled borrowing and prompted asset prices to soar.

${ }^{14}$ It is therefore not surprising that the Austrian and Swiss housing markets are also under close surveillance. The overall assessment of the market development is that the Swiss house price level clearly lies in the risk zone. For example, The "UBS Swiss Real Estate Bubble Index 2012Q4” clearly shows the alarming imbalances in the Swiss residential housing market and associated risks accruing to the Swiss economy. See http://www.ubs.com/global/de/wealth_management/wealth_management_research/bubble_index.html. In the 2012 Financial Stability Report and in the March 2013 Swiss National Bank Quarterly Bulletin the Swiss National Bank concluded that signs of an overvaluation of house prices have strengthened. The overall assessment is that the risks of high prices triggering a substantial subsequent price correction have increased sharply. See http://www.snb.ch/en/mmr/reference/quartbul_2013_1_komplett/source/quartbul_2013_1_komplett.en.pdf and http://www.snb.ch/en/mmr/reference/stabrep_2012/source/stabrep_2012.en.pdf. For a recently published stress testing Austrian National Bank analysis of the rising housing cost burden of households, see http://www.oenb.at/en/img/mop_2012_q4_analyses4_tcm16-253970.pdf. 
Figure 1: Recent House Price Changes Across OECD Countries, 2010 - 2012

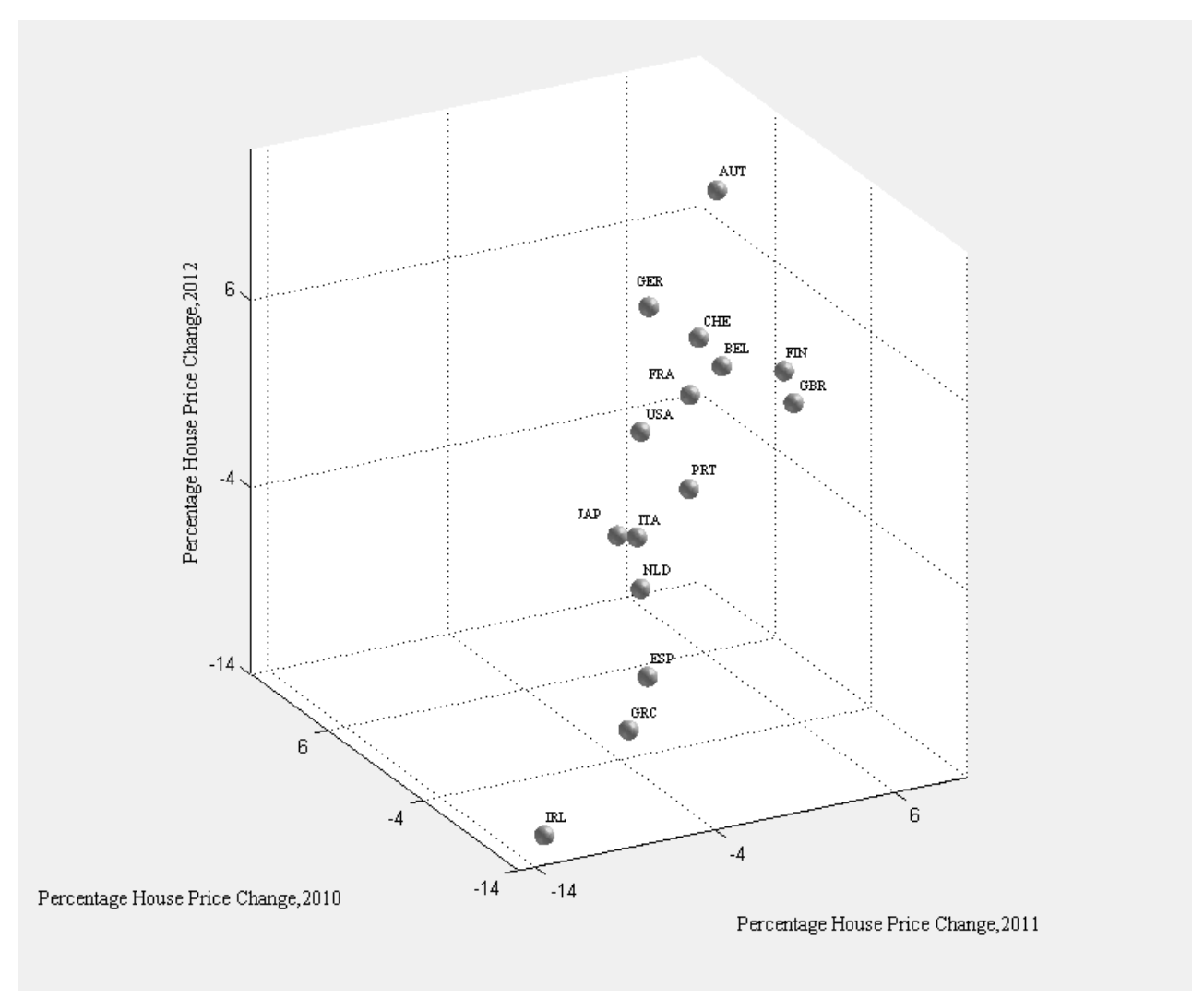

The underlying feature for these varying developments is that housing cycles usually last for more than a decade. This long memory in house price data means that the current downswing evident in several countries is likely to persist over a long period of time. ${ }^{15}$ All in all, one can conclude that Germany is one of a few countries constituting special cases. Of course, strong house price increases in a few years are not necessarily evidence of overvaluation. To address this issue, one has to put the current period of house price increases into historical perspective. Furthermore, it is necessary to relate house prices to their putative underlying determinants. To this end, Figure 2 and 3 present seasonally adjusted quarterly time series for German nominal and real house prices and the associated price-to-rent ratio for 1971Q1 - 2012Q4, respectively.

\footnotetext{
${ }^{15}$ Drehmann et al. (2012) have recently characterised empirically the financial cycle and its relationship with the business cycle. The analysis shows that the medium-term financial cycle is a different phenomenon from the business cycle. Furthermore, the length and amplitude of financial cycles have increased markedly since the mid1980s. The IMF (2003) has documented the information content of house prices for both business cycles and systemic banking crises with serious macroeconomic dislocations.
} 
Figure 2: German Nominal and Real House Prices, 1971Q1-2012Q4, Indices 2010 = 100

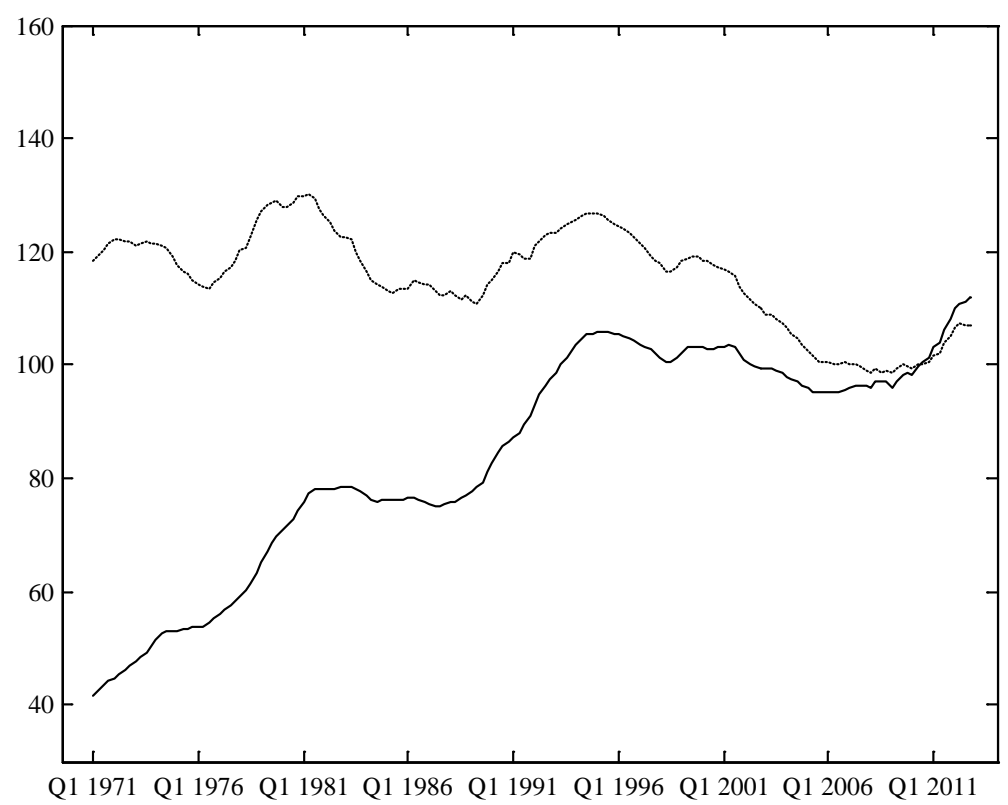

Note: The solid (dashed) line represents the seasonally-adjusted quarterly nominal (real) house price index. Real house prices are deflated by the CPI.

Figure 3: German Price-To-Rent-Ratio, 1971Q1-2012Q4, Index 2010 = 100

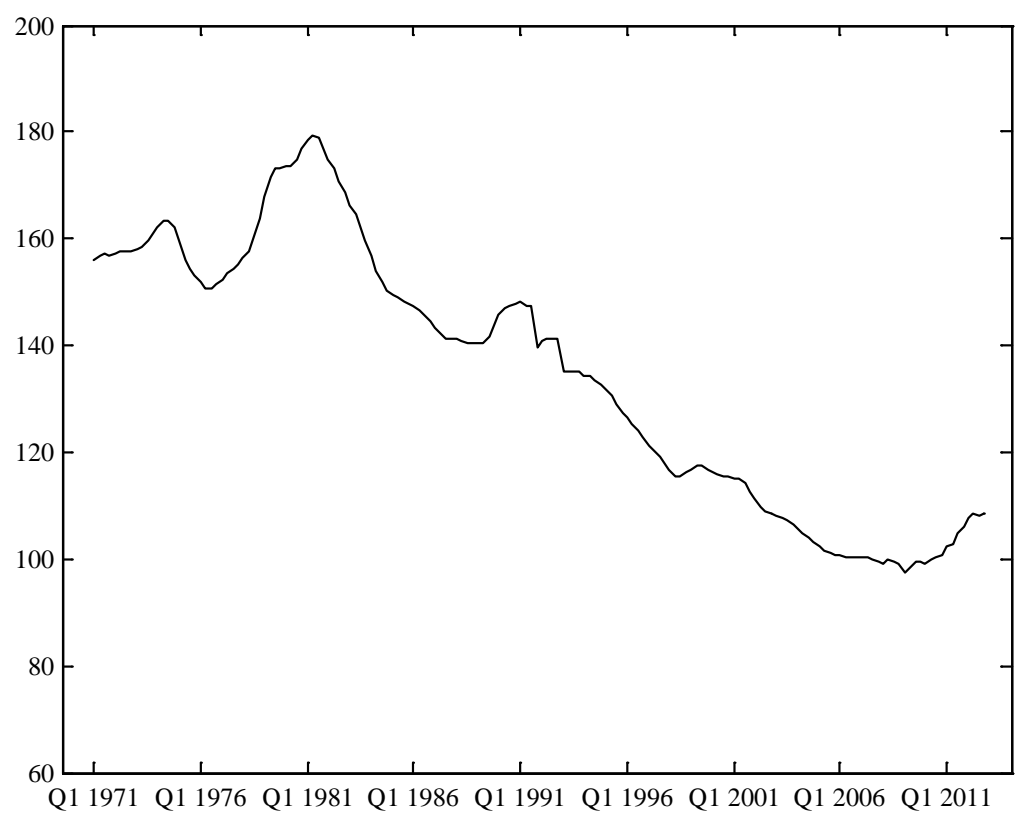

Over the last 30 years, nominal house prices in Germany have been growing rather moderately, whereas real house prices have been stagnating or even declining, especially over the last 10 years., German 
house prices - both in nominal and real terms - have only started to rise since $2010 .{ }^{16}$ Consequently, German house prices have been moving in opposite direction to those in other countries: while in the majority of OECD countries the early 2000s had been characterized by a strong house price increase (especially, in Ireland, Spain, the Netherlands and the UK), which culminated 2007-2008 in a spectacular burst of speculative house price bubbles, starting from 1995 German house prices have been going down and have only recently recovered from their protracted decline.

Another summary measure used to get an indication of over or undervaluation is the price-to-rent ratio (the nominal house price index divided by the rent component of the consumer price index). This measure, which is akin to a price-to-dividend ratio in the stock market, could be interpreted as the cost of owning versus renting a house. When house prices are too high relative to rents, potential buyers find it more advantageous to rent, which should in turn exert downward pressure on house prices. Unlike in many other countries, the price-to-rent ratio in Germany steadily declined until 2010 when the ratio began to rebound.

What does this mean for macroprudential market surveillance? Systemic risk in the housing market has to be addressed preemptively at an early stage of the bubble. However, preemption is difficult in the context of tail events that are experienced after long time intervals of moderate house price changes during which public memory of past asset price bubbles has faded. In the next section of the paper we shall implement the recursive GSADF bubble dating algorithm outlined above to locate periodic explosive periods.

\section{Estimation results}

Could Germany be heading for a housing bubble? In order to identify speculative house price bubbles, the fundamental part of house prices has to be separated from the speculative part. There are various ways to estimate the fundamental value of house prices. The asset pricing equation (2) suggests looking at the German price-to-rent ratio as a yardstick, i.e. house price changes should be in line with rental changes, given constant interest rates. A corollary of this is that the price-to-rent ratio should be constant over time in the absence of a speculative bubble. When house prices are low relative to rent, future increases in house prices are likely to be high. Thus, the price-to-rent ratio can be viewed as "an indicator of valuation in the housing market” [Gallin (2008), p. 635]. In the following, we will therefore

\footnotetext{
${ }^{16}$ It is well known that house price developments are uneven. At present, Germany experiences a wide range of appreciation in house prices, with house prices in the largest cities increasing at a faster pace. Therefore, one might argue that closer inspection should be placed on city-level house price developments. Yet, this argument is not very conclusive. This is because macroprudential policy measures would have nationwide effects in all geographic areas of the country, not just in those areas where house prices are rising rapidly. Therefore, a widely held view is that macroprudential and monetary policies should focus only on aggregate economic conditions because they cannot control or target the conditions of particular geographic regions. Another important (and perhaps underappreciated) issue related to this is an insufficient city-level house price data availability and quality.
} 
apply the real-time dating method to the price-to-rent ratio behaviour to detect emerging bubbles using quarterly data from 1980Q1 to 2012Q4. A delicate point of the procedure is the choice of the fractional window size of the regression. Suppose the minimum number of observation used in any regression is $r_{0} T$, for some fraction $r_{0} \in(0,1)$. So far, no automatic algorithm for the selection of $r_{0}$ is available. In our application, we choose $r_{0}=0.4$. Robustness checks indicate that the picture painted by Figure 4 does not change for changes in $r_{0} \cdot{ }^{17}$ The beginning of the bubble is estimated as the first date when the GSADF statistic is greater than its corresponding critical value. The end of the speculative bubble will be determined as the first period when the GSADF statistic is below the aforementioned critical value. The finite sample critical values are obtained via Monte Carlo simulations with 2,000 iterations. These simulations incorporate the sampling uncertainty of the data generating process. We rely on the critical values to determine the optimal thresholds. All calculations have been executed in the Matlab programming environment. Figure 4 provides the house price bubble barometer for Germany. The solid black line shows the recursively calculated GSADF statistic sequence, along with the associated 95 percent (green line) and 99 percent (red line) critical values, respectively. The dashed line gives the real house price index.

\section{Figure 4: Recursive Calculation of the GSADF Test for Germany}

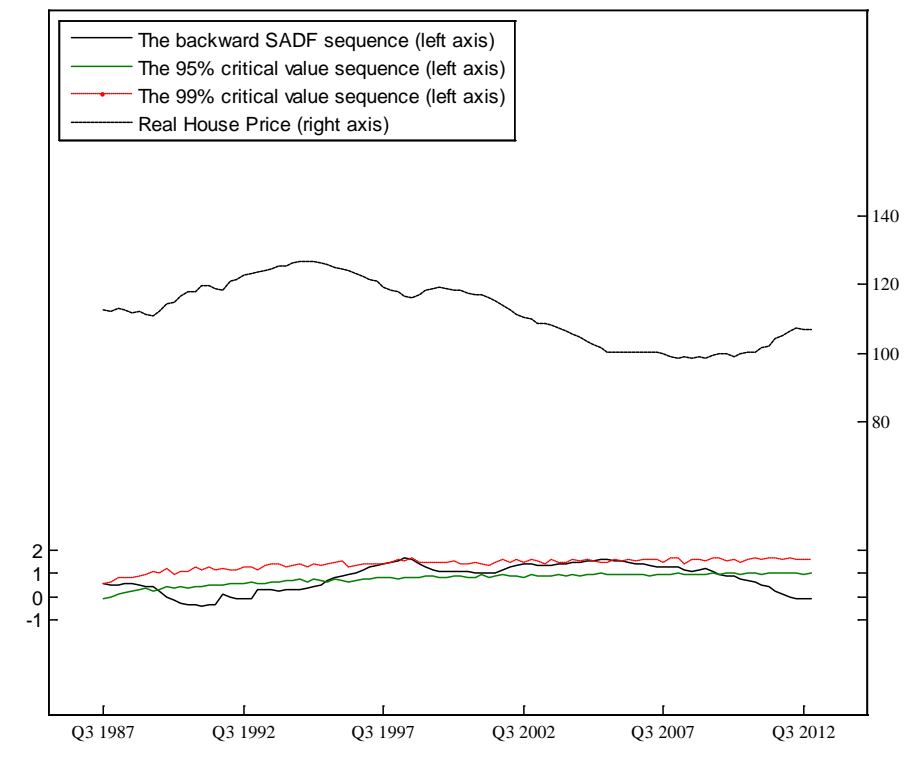

At first glance it turns out that the continuously evolving GSADF statistics signal no statistically significant periodic misalignment at the 1 percent significance level. In other words, German house

\footnotetext{
${ }^{17} 168$ observations and $r_{0}=0,4$ yield a minimum window size of 67 . Then employing the algorithms, we obtain the backward SADF sequence from 1987Q3 onwards. The choice of $r_{0}$ may also be thought of as a trade-off between efficiency and robustness.
} 
prices were out of the significant danger zone. It is noticeable that this confirms the preliminary results illustrated by Figure $3 .^{18}$

But things are not that simple. Unfortunately, early warning indicators don't "make” definite diagnoses; they supplement a careful housing market monitoring and reduce the level of monitoring uncertainty. While after the global recession 2008-2009 real-time warning systems of housing bubbles were a much sought-after diagnostic tool, there is also a lot of skepticism on the ability to predict housing crises or, more generally, any type of financial crises. This skepticism stems from the alleged poor out-of-sample performance of many early warning models. Diagnostics are rarely 100 percent accurate, so false positives and false negatives can occur. Notwithstanding the sophistication of the statistical toolbox described above, any proposed real-time warning indicator is certain to face challenges in generating "misses" rather than "hits". It is therefore an open question whether the line of enquiry presented above proves empirically fruitful. A reliable real-time warning indicator would correctly call all bubbles and would not issue bubble announcements unnecessarily. Erroneous misses represent a failure to call a bubble (false negative type I error), while erroneous hits generate a false alarm (false positive type II error). It should be borne in mind that there is an inherent trade-off between type I and type II errors which are both functions of the chosen significance level. Changing the significance level to allow more housing bubbles to be picked up necessarily raises the likelihood of false bubble alarms. Traditionally, monetary policymakers tended to have a stronger preference for missing crises than to act on noisy signals. The global financial crisis 2008-2009 may have changed that. In other words, policymaker concerned with avoiding housing bubbles may now choose to minimise type I errors even if this entails unnecessary macroprudential policy intervention. One rationale behind this could be that monetary policymakers are willing to take a "bubble insurance" and to accept a possible false alarm rather than be taken by surprise by a financial crisis.

One simple way of assessing the genuine validity and reliability of the univariate screening toolkit is to calculate the statistics across a range of countries known to have experienced boom/bust episodes in the global recession 2008-2009. ${ }^{19}$ In defence of our real-time warning signal we have therefore also calculated the test statistics for Ireland, Spain, the Netherland, the UK, and the U.S. This allows one to determine the accuracy of the indicator, i.e. the cross-country comparison provides a rough indication of the type I and type II error rates of our statistical toolkit. It may also help to dispel misconceptions that people have about early warning indicators. Again we have applied the real-time dating method to the price-to-rent ratio behaviour to detect emerging bubbles using quarterly data from 1971Q1 to 2012Q4 (left axis). In addition, the real house price indices are also plotted (dashed lines; right axis). The results

\footnotetext{
${ }^{18}$ At the very most, the procedure flashed some borderline „red flags“ in the mid 1990s which coincides with the concurrent increase in house prices.

${ }^{19}$ In most countries only one (most recent) house price boom-bust-cycle can be analysed. Thus although the sample is long enough for sound econometric analysis, the informational content along the time dimension is selective. However, it is reassuring that the indicator matches the two turning points for housing busts in Spain in 1991Q4 and the UK in 1989Q3 documented in IMF (2003), p. 91.
} 
of our screening indicator's ability to correctly identify bubble periods are available in Figure $5-9$ below.

Figure 5: Recursive Calculation of the GSADF Test for Ireland

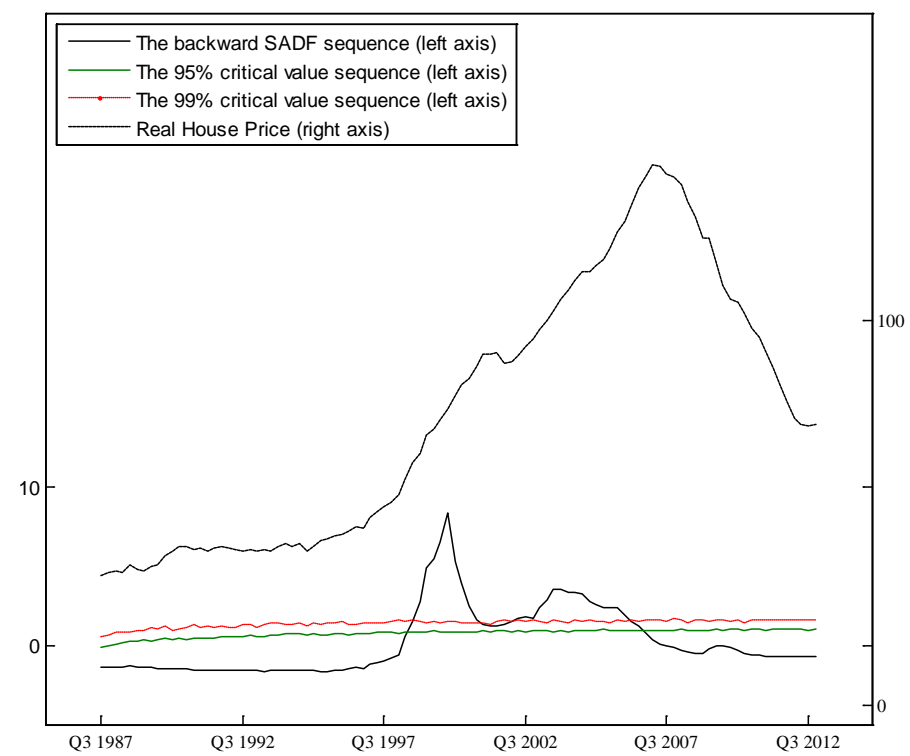

Figure 6: Recursive Calculation of the GSADF Test for the Netherlands

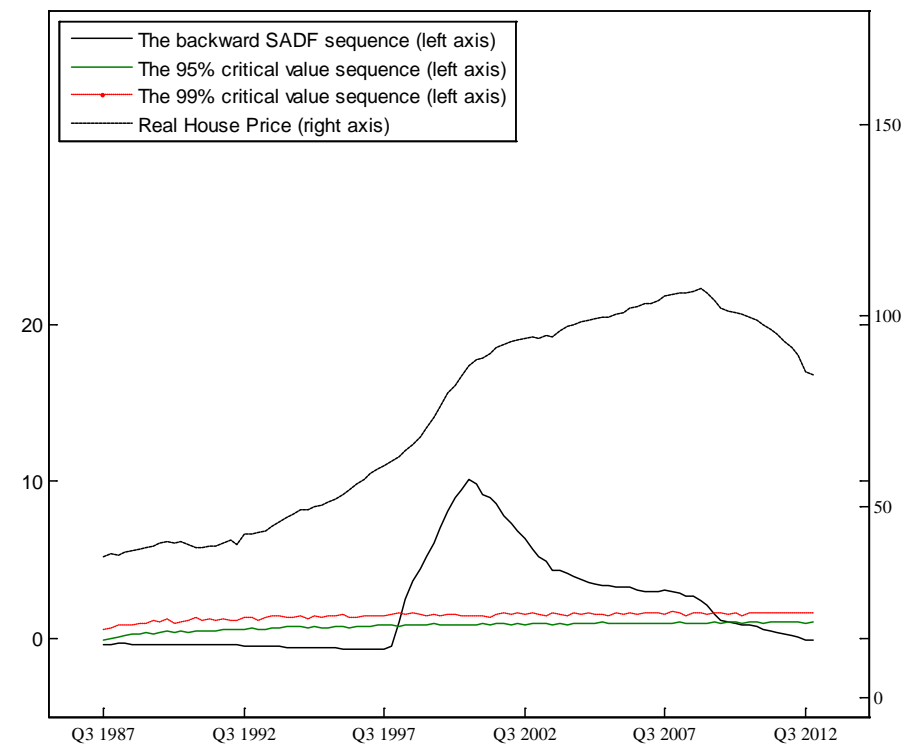


Figure 7: Recursive Calculation of the GSADF Test for Spain

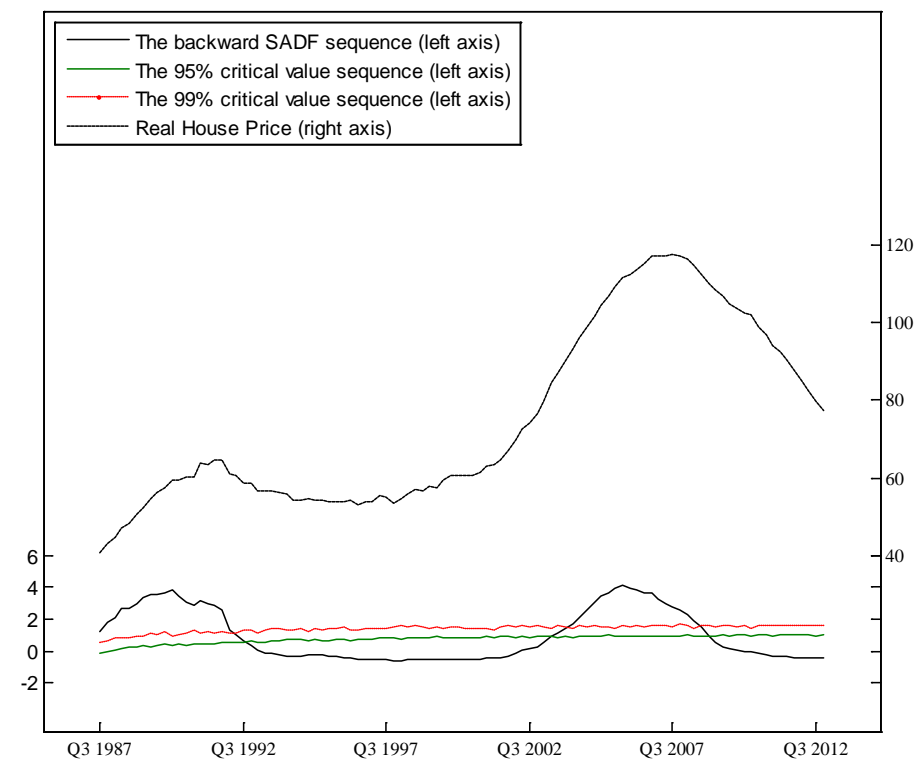

Figure 8: Recursive Calculation of the GSADF Test for the UK

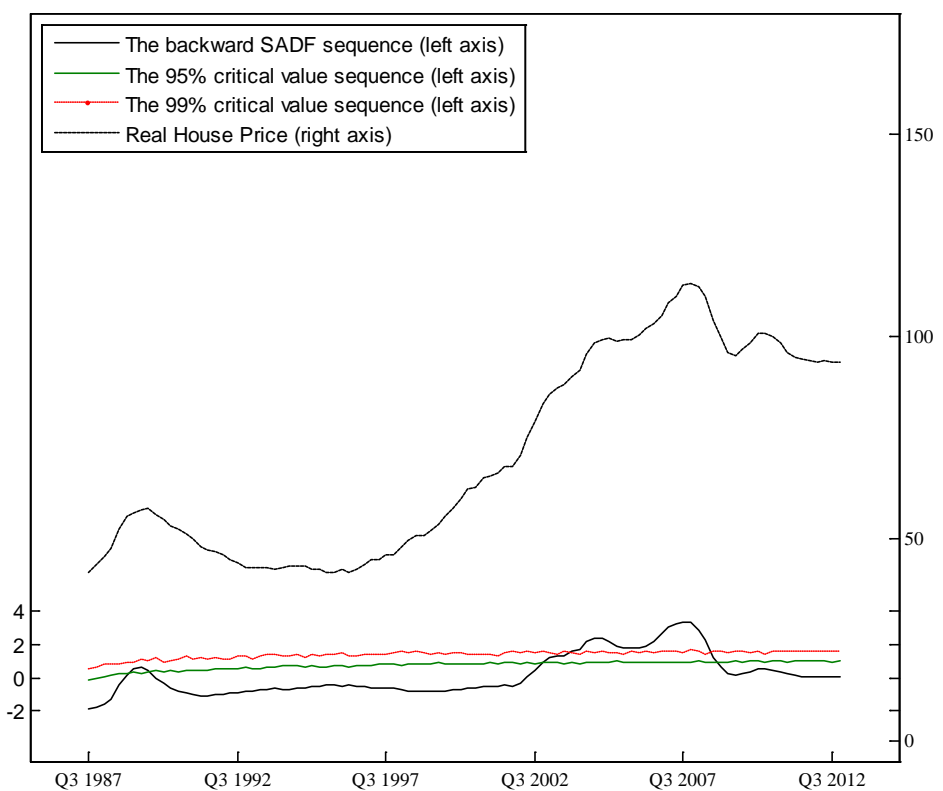




\section{Figure 9: Recursive Calculation of the GSADF Test for the U.S.}

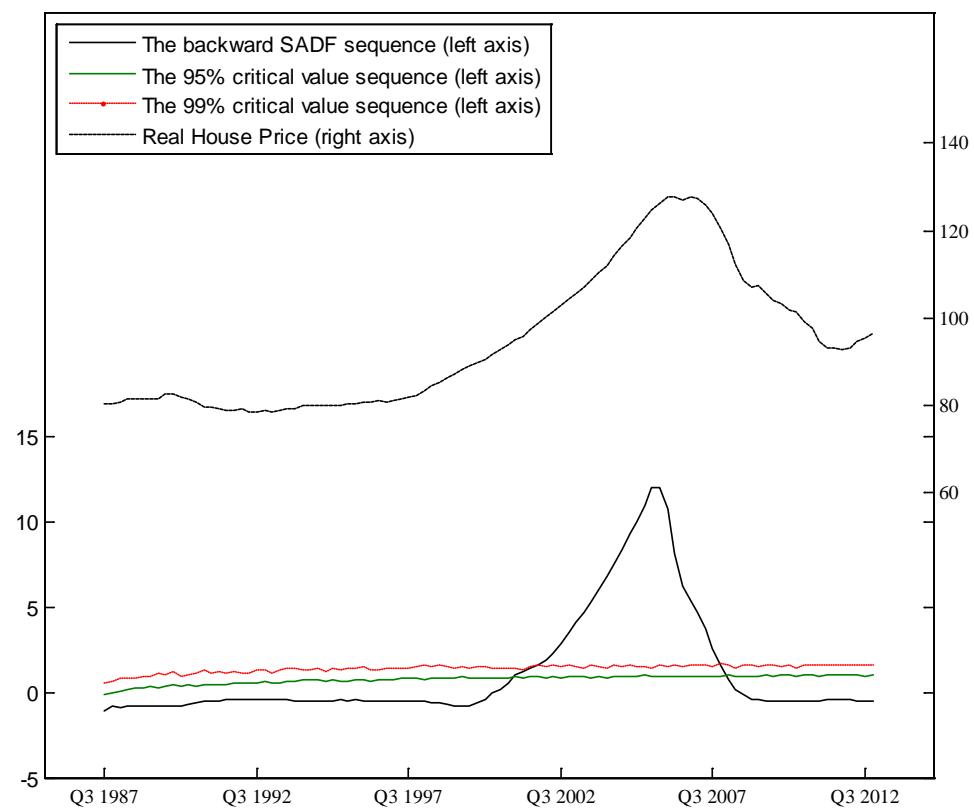

Casting the net more widely for illustrative purposes, and looking across several "housing bubble countries”, the following results warrant attention. The visual inspection of Figure 5 - 9 shows the fundamental suitability of the GSADF house price bubble early warning indicator. Note that despite the simple methodology employed the real-time predictive content is remarkably good and delivers a cohesive picture. In all countries the statistic signalled the build-up of risk and forthcoming trouble in real time with fairly good accuracy. This early warning in all countries leads one to reject the existence of type I error. On the other hand, the indicator is apparently fraught with type II errors. Examples are Ireland and the Netherland, where the signals flashed at the end of the 1990s but these warning signs did not culminate into bursting bubble until 2007-2008. Therefore a country may be vulnerable in the sense that the GSADF statistic is signalling trouble, yet a bursting bubble may be averted through good luck and/or good policies. On the other hand, synchronised house price shocks across countries may reinforce each other and may lead to a significant increase in the probability of a bursting housing bubble in one country, conditional on a bursting housing bubble occurring in another country and exposure to the foreign cycle. Finally, it should be noted that the probability of a crisis typically increases the larger the house price increase and the longer the duration of the boom is. This mechanism linking asset booms to crisis is clearly visible for the U.S. indicator in Figure 9. To summarise, the flagraising GSADF statistic in Figure 9 indicates that the synchronised global crisis 2008-2009 originated in the U.S. with the unravelling of the subprime U.S. mortgage market and has quickly spread to the European countries, due to asset price linkages and in particular the process of securitisation and reinsurance in the derivatives market across banks worldwide. This has triggered credit crunches and consequent economic crises in various advanced countries. In addition, informational cascades and herding by agents, unregulated off-balance sheet vehicles and/or correlated risk premia across countries 
have also transmitted the U.S. shock to other countries. This shift-contagion has led to the global recession 2008-2009.

Overall, the evidence in Figure 5 - 9 delivers timely warnings of underlying misalignments, vulnerabilities, and tail risks that predisposed the international housing markets to the crisis 2008 2009. This gives us confidence in the potential applicability of the proposed testing strategy to German house price data in Figure 4. Lacking a gold standard procedure for detecting house price bubbles, an early warning bubble test with high sensitivity can be considered as a reliable indicator when its result is negative, since it rarely misses true positives among those who are actually positive. Put differently, highly sensitive diagnostics have few false-negative results and are therefore most useful to rule out a beginning decoupling of house prices from their underlying fundamentals. Such highly sensitive diagnostics should particularly be used when we need to detect house price exaggerations and flag vulnerabilities in real time. Finally, the estimation results can also be interpreted as an indirect validation of the main argument put forth in Reinhart and Rogoff's (2009) book This Time is Different. Therein they have provocatively argued that there are strong regularities attached to financial crises, which are therefore predictable based on economic fundamentals.

\section{Wrapping up: signalling the build-up of risk with univariate time series methods}

It is sometimes alleged that monetary policy is closer to art than to science because it is frequently confronted to new, poorly anticipated and poorly understood, developments and shocks. It is claimed that in such situations common sense and experience are more powerful tools than a slavish adherence to theoretical and econometric models.

Since the global recession 2008-2009, the emphasis on systemic risk assessment and macro stress tests has gained importance. When rapid increases in house prices occur, concerns are frequently voiced that prices may have lost touch with the underlying fundamentals. In such a circumstance, there is the fear a bubble may be developing that may eventually burst. This can potentially impart ripple effects throughout the rest of the economy. The main objective of this paper is not to pretend that a simple model can predict emerging bubbles perfectly, but rather to show that even a parsimonious univariate statistical toolbox can do a good job at indicating housing market vulnerabilities in real time. To this end we have employed the state-of-the-art GSADF unit root tests suggested by Phillips and Yu (2011) and Phillips et al. (2012) as a barometer. The methodology offers a simple and straightforward real-time monitoring of housing cycles. Based on the GSADF statistic, so far there is no reason to believe that a German housing bubble is emerging.

It is important to stress that, just as any other methodology for estimating early warning indicators of house price bubbles, this one is not a panacea. Nevertheless it is hoped that it will help to move the debate forward on this vital topic. However, whether this line of enquiry will ultimately prove fruitful and paves the way for early enough macroprudential policies is a legitimate subject of debate. In terms 
of macroprudential policy, results suggested here should be interpreted carefully and should only be considered as part of a suite of indicators used in a complementary manner.

\section{References:}

Abreu, D. and M.K. Brunnermeier (2003) “Bubbles and Crashes”, Econometrica 71, 173-204.

Agnello, L. and L. Schuknecht (2011) "Booms and Busts in Housing Markets: Determinants and Implications”, Journal of Housing Economics 20, 171-190.

Agur, I. and M. Demertzis (2013) “'Leaning Against the Wind' and the Timing of Monetary Policy”, IMF Working Paper No. WP/13/86, Washington.

Alessi, L. and C. Detken (2011) "Quasi Real Time Early Warning Indicators for Costly Asset Price Boom/Bust Cycles: A Role for Global Liquidity”, European Journal of Political Economy 27, 520-533.

Busetti, F. and A.M.R. Taylor (2004) “Tests of Stationarity Against a Change in Persistence”, Journal of Econometrics 123, 33-66.

Case, K.E. and R.J. Shiller (2003) "Is There a Bubble in the Housing Market?”, Brookings Papers on Economic Activity 34, 299-362.

Claessens, S., Kose, M.A. and M.E. Terrones (2009) "What happens during Recessions, Crunches, and Busts?”, Economic Policy 24, 653-700.

Crespo Cuaresma, J. (2010) “Can Emerging Asset Price Bubbles be Detected?” OECD Economics Department Working Papers No. 772, Paris.

Daniel, K., Hirshleifer, D. and A. Subrahmanyam (19989 “Investor Psychology and Security Market Under- and Overreactions”, Journal of Finance 53, 1839-1885.

DeLong, Bradford, J., Shleifer, A., Summers, L. and R.J. Waldmann (1990) "Positive Feedback Investment Strategies and Destabilizing Rational Speculation”, Journal of Finance 45, 375-395.

Deutsche Bundesbank (2012) “German Housing Market Gaining Momentum”, in: Financial Stability Review 2012, 55-65.

Diba, B.T. and H.I. Grossman (1987) “On the Inception of Rational Bubbles”, Quarterly Journal of Economics 102, 697-700.

Diba, B.T. and H.I. Grossman (1988) "The Theory of Rational Bubbles in Stock Prices”, Economic Journal 98, 746-754.

Drehmann, M., Borio, C. and K. Tsatsaronis (2012) “Characterising the Financial Cycle: Don’t Lose Sight of the Medium Term!”, BIS Working Paper No 380, Basel.

European Central Bank (2002) “The Stock Market and Monetary Policy”, ECB Monthly Bulletin, February 2002, 39-52.

European Central Bank (2005) “Asset Price Bubbles and Monetary Policy”, ECB Monthly Bulletin, April 2005, 47-60. 
European Central Bank (2010) “Asset Price Bubbles and Monetary Policy Revisited, ECB Monthly Bulletin, November 2010, 71-83.

Evans, G. (1991) "Pitfalls in Testing for Explosive Bubbles in Asset Prices", American Economic Review 81, p. 922-930.

Funke, M., Hall, S. and M. Sola (1994) "Rational Bubbles during Poland's Hyperinflation: Implications and Empirical Evidence”, European Economic Review 38, p. 1257-1276.

Funke, M. and M. Paetz (2013) "Housing Prices and the Business Cycle: An Empirical Application to Hong Kong”, Journal of Housing Economics 22, 62-76

Gallin, J. (2008) “The Long-Run Relationship Between House Prices and Rent”, Real Estate Economics 36, 635-658.

Gerdesmeier, D., Lenarèiè, A. and B. Roffia (2012) „An Alternative Method for Identifying Booms and Busts in the Euro Area Housing Market”, European Central Bank Working Paper No. 1493, Frankfurt.

Gilboa, I. and D. Schmeidler (1989) "Maxmin Expected Utility with Nonunique Prior", Journal of Mathematical Economics 18, 141-153.

Gürkaynak, R.S. (2008) "Econometric Tests of Asset Price Bubbles: Taking Stock”, Journal of Economic Surveys 22, p. 166-186.

Himmelberg C., Mayer C. and T. Sinai (2005) “Assessing High House Prices: Bubbles, Fundamentals and Misperceptions”, Journal of Economic Perspectives 19, 67-92.

Hirata, H., Kose, M.A., Otrok, C. and M.E. Terrones (2013) "Global House Price Fluctuations: Synchronization and Determinants”, IMF Working Paper WP/13/38, Washington.

Hong, H. and J.C. Stein (1999) “A Unified Theory of Underreaction, Momentum Trading, and Overreaction in Asset Markets”, Journal of Finance 54, 2143-2184.

Iacoviello, M. and R. Minetti (2008) "The Credit Channel of Monetary Policy: Evidence from the Housing Market”, Journal of Macroeconomics 30, 69-96.

Iacoviello, M. and S. Neri (2010) "Housing Market Spillovers: Evidence from an Estimated DSGE Model”, American Economic Journal: Macroeconomics 2, 125-164.

Igan, D. and P. Loungani (2012) “Global Housing Cycles”, IMF Working Paper WP/12/217, Washington.

IMF (2003) “When Bubbles Burst”, World Economic Outlook, April 2003, pp. 61-94, Washington.

IMF (2012) Germany 2012 Article IV Consultation, Washington.

Kim, T.-H., Leybourne, S. and P. Newbold (2002) "Unit Root Tests with a Break in Innovation Variance”, Journal of Econometrics 109, p. 365-387.

Leybourne, S.J., Kim, T.H. and A.M.R. Taylor (2006) "Regression-Based Tests for a Change in Persistence”, Oxford Bulletin of Economics and Statistics 68, p. 595-621.

Phillips, P.C.B., Shi, S. and J. Yu (2012) Testing for Multiple Bubbles. Cowles Foundation Discussion Paper No. 1843, Yale. 
Phillips, P.C.B., Wu, Y. and J. Yu (2011) "Explosive Behavior in the 1990s NASDAQ: When Did Exuberance Escalate Asset Values?”, International Economic Review 52, p. 201-226.

Phillips, P.C.B., and J. Yu (2011) "Dating the Timeline of Financial Bubbles During the Subprime Crisis”. Quantitative Economics 2, p. 455-491.

Reinhart, C. M. and K. M. Rogoff (2009) This Time is Different - Eight Centuries of Financial Folly, Princeton (Princeton University Press).

Schaller, H. and S. van Norden (2002) “Fads or Bubbles?” Empirical Economics 27, p. 335-362.

Scheinkman, J.A. and W. Xiong (2003) “Overconfidence and Speculative Bubbles”, Journal of Political Economy 111, 1183-1219.

Shiller, R.J. (2002) “Bubbles, Human Judgment, and Expert Opinion”, Financial Analysts Journal 58, 18-26. 